\title{
RIDDLES OF THE TEXT OF AN EARLY BYZANTINE HISTORIAN (Book Review: Priscus Panita. Excerpta et fragmenta / ed. by P. Carolla. - Berolini ; Novi Eboraci : Walter de Gruyter, 2017. - XLVIII, 140 p.)
}

\author{
Alexander S. Kozlov \\ Ural Federal University named after the first President of Russia B.N. Yeltsin, \\ Yekaterinburg, Russian Federation
}

\begin{abstract}
Introduction. The publication is a review of the critical edition of the preserved fragments of the Early Byzantine intellectual and diplomat Priscus Panita's historical work who presented first of all unique information about the nature of international relations in the Eastern Mediterranean and in Europe at the time of increasing threats to the Eastern and Western Roman empires from the barbarians. Analysis. Italian scholar, philologist, and archaeographer P. Carolla who, unlike many of her predecessors, involved all the codices containing excerpts from the writings of Priscus for the publication, primarily confirmed the concept of her teacher, F. Bornmann, about the authenticity of texts related to the work of Priscus, but contained in the works created under control of the $10^{\text {th }}$-century emperor Constantine VII. The result of the presentation of these fragments is a logical series of formally separate texts which is based on a perfectly developed stem. This kind of classical archaeographic technique is supplemented by approaches different in their effectiveness to the publication of excerpts whose affiliation to the Priscus' pen is not indisputable. The review notes that this kind of technique would have been more successful if Carolla had accompanied the published texts with a commentary on their content. But there are no such comments, but only some attempts to indicate that a number of passages belong to Priscus as an author. This approach impoverishes publisher's archaeographic finds and is methodologically flawed. The disadvantages of such methods of publication are illustrated in the review by examples of hypothetical dependence of the corresponding "Hunnic" passages of the most famous historian of the $6^{\text {th }}$-century Byzantium Procopius of Caesarea on the texts of Priscus. Results. In general, however, the publication undertaken by Carolla not only presents well-organized topical texts to specialists, allowing them to expand the possibilities of studying the transition from Antiquity to the Middle Ages, but also gives an additional impetus to improving the methodology of Byzantine archaeography.

Key words: Early Byzantium, Early Byzantine historiography, Priscus Panita, Byzantine archaeography, publication of Byzantine sources.

Citation. Kozlov A.S. Riddles of the Text of an Early Byzantine Historian (Book Review: Priscus Panita. Excerpta et fragmenta / ed. by P. Carolla. - Berolini ; Novi Eboraci : Walter de Gruyter, 2017. - XLVIII, 140 p.). Vestnik Volgogradskogo gosudarstvennogo universiteta. Seriya 4. Istoriya. Regionovedenie. Mezhdunarodnye तิ otnosheniya [Science Journal of Volgograd State University. History. Area Studies. International Relations], 2020, خे vol. 25, no. 6, pp. 285-291. (in Russian). DOI: https://doi.org/10.15688/jvolsu4.2020.6.23
\end{abstract}




\title{
ЗАГАДКИ ТЕКСТА РАННЕВИЗАНТИЙСКОГО ИСТОРИКА (Рец. на кн.: Priscus Panita. Excerpta et fragmenta / ed. by P. Carolla. - Berolini ; Novi Eboraci : Walter de Gruyter, 2017. - XLVIII, 140 p.)
}

\author{
Александр Сергеевич Козлов \\ Уральский федеральный университет им. первого Президента России Б.Н. Ельцина, \\ г. Екатеринбург, Российская Федерация
}

\begin{abstract}
Аннотация. Публикация представляет собой рецензию на критическое издание сохранившихся фрагментов исторического труда ранневизантийского интеллектуала и дипломата Приска Панийского, презентовавшего прежде всего уникальные сведения о характере международных отношений в Восточном Средиземноморье и в Европе во времена нарастания угроз Восточной и Западной Римским империям со стороны варваров. Привлекая для публикации, в отличие от многих своих предшественников, все кодексы, содержащие отрывки из сочинения Приска, итальянская исследовательница, филолог и археограф П. Каролла прежде всего подтвердила концепцию своего учителя, Ф. Борнманна, об аутентичности текстов, соотносимых с сочинением Приска, но содержащихся в трудах, созданных под руководством императора X в. Константина VII. Результатом презентации этих фрагментов становится логичный ряд формально отдельных текстов, в основе которого находится безупречно разработанная стемма. Такого рода классическая археографическая методика дополняется разными по степени эффективности подходами по приобщению к изданию эксцерптов, чья принадлежность перу Приска не бесспорна. В рецензии отмечается, что такого рода методика была бы успешнее, если бы Каролла сопровождала публикуемые тексты комментарием их содержания. Но таких комментариев нет, есть лишь отдельные попытки указаний на сомнительность принадлежности ряда пассажей Приску как автору. Такой подход обедняет археографические находки издателя и методологически небезупречен. Недостатки подобных приемов издания иллюстрируются в рецензии примерами гипотетической зависимости от текстов Приска соответствующих «гуннских» пассажей самого знаменитого историка Византии VI в. Прокопия Кесарийского. В целом, однако, предпринятое Кароллой издание не только презентует специалистам добротно организованные актуальные тексты, позволяющие расширить возможности изучения перехода от Античности к Средневековью, но также дает дополнительный импульс к совершенствованию методики византиноведческой археографии.
\end{abstract}

Ключевые слова: Ранняя Византия, ранневизантийская историография, Приск Панийский, византиноведческая археография, издание византийских источников.

Цитирование. Козлов А. С. Загадки текста ранневизантийского историка (Рец. на кн.: Priscus Panita. Excerpta et fragmenta / ed. by P. Carolla. - Berolini ; Novi Eboraci : Walter de Gruyter, 2017. - XLVIII, 140 p.) // Вестник Волгоградского государственного университета. Серия 4, История. Регионоведение. Международные отношения. - 2020. - Т. 25, № 6. - C. 285-291. - DOI: https://doi.org/10.15688/jvolsu4.2020.6.23

Введение. Осуществляемое с помощью новейших археографических методик издание наследия Приска Панийского, одного из самых актуальных для реконструкции международных отношений в Европе и на Ближнем Востоке V в., - задача тяжелая в силу сложности эвристики материла в разнородных кодексах [1, p. 19-22; 4, p. 290-291; 10, p. VII-X]. Но, как известно, труд Приска это захватывающий рассказ о власти и интригах в позднеантичной Византии, о ее отношениях с державой гуннов, царя которых, Аттилу, Приск посещал в составе дипломатичес- кой миссии. Мало того, и поныне многие политики, интеллектуалы и просто интересующиеся находят в строках Приска уникальные сведения о корнях ряда народов Центральной и Юго-Восточной Европы, Ближнего Востока и Северной Африки [7, p. 146-160]. Для филологов-классиков эти тексты заполняют пробелы в конструировании точного археографического аппарата и аутентичной презентации stemma codicum [10, p. XVII]. Основная трудность в том, что фрагменты «Истории» Приска разбросаны по разнородным по жанру и сохранности византийским сочинениям и мно- 
гие из этих отрывков сложно соотнести с наследием Панийца.

Анализ. Довольно быстрое (для Тойбнеровской серии) переиздание дошедших до

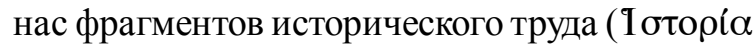

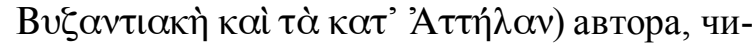
новника и дипломата $\mathrm{V}$ в. ${ }^{1}$ подчеркивает устойчивую востребованность в критическом, сделанном по всем современным правилам компендиуме всех известных списков этого уникального сочинения. Как известно, до недавних пор специалисты вынуждены были пользоваться изданиями фрагментов Приска, выполненными прежде всего К. Мюллером (1851, 1870 гг.) и Л. Диндорфом (1870 г.), не включавшими все сохранившиеся codices. То же самое касалось изданий эксцерптов из сочинений Константина Багрянородного, в соста-

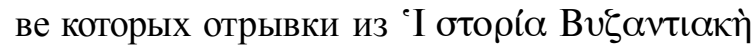
наличествовали в первую очередь. В 1979 г. специалисты, однако, получили издание Ф. Борнманна (впервые включившее в себя все известные эксцерпты Приска, содержащиеся в книгах Константина VII и бытующие вне их, а также соответствующие разделы из «Суды»), а в 1981 г. - издание Р. Блокли, вобравшее в себя, кроме всего прочего, тексты из сочинений других грекоязычных историков, прямо или косвенно восходивших к традиции Панийца [3]. Особо следует отметить, что Блокли, расположив фрагменты из труда Приска по-своему, придал новый взгляд на композицию 'I oтоюí $\alpha$ В $\zeta \alpha v \tau \iota \alpha$ ฑे. Смущающим моментом, однако, стало то, что в некоторых случаях английский историк расчленил эксцерпты Константина VII на отдельные части.

П. Каролла, издавая фрагменты исторического сочинения Приска (его риторические изыскания и письма до нас не дошли), по сути продолжает работу своего учителя Ф. Борнманна и прежде всего его концепцию относительно достоверности собраний эксцерптов, презентуемых Константином VII как аутентичные тексты [10, p. VII]. Исследовательница исходит из того, что компиляторы крайне незначительно перерабатывали свои протографы, заботясь о сохранении текста оригинала [10, p. XXXII]. Посему, по ее мнению, выписка отдельных мест из текста Панийца в целом была проделана весьма корректно. Однако надо сказать, что в качестве аргумента на сей счет она привлекает и сообщения «Гетики» Иордана, для которых Приск был источником, хотя называть подобные пассажи остготского историка «извлечениями» я бы не стал.

В самом деле, в первом (и наибольшем по объему) компендиуме издаваемых фрагментов (сюда вошли Excerpta de legationibus [10, p. 1-3]; Excerpta de insidiis [10, p. 4]; Excerpta de legationibus sequuntur [10, p. 5-80]; Excerpta incertae sedis [10, p. 81-82]) мы видим прежде всего извлечения из Excerpta de legationibus, а также два фрагмента из Excerpta de insidiis (exc. 1a-1b) Константина VII. Однако к эксцерптам Каролла относит и ряд сообщений из Иордана (например, ехс. 9, 10, 17) и «Суды» (например, ехс. 11). То есть в данном компендиуме оказались по соседству фрагменты весьма разного (в том числе - и авторского, и жанрового) происхождения. Как их можно было поместить в разделе, однозначно сопряженном с именем Константина VII (Excerpta de legationibus), непонятно. Кроме того, таким методом под именование эксцерптов из Константина VII оказываются подведены как подлинные извлечения из трудов Константина VII, так и фрагменты, восходящие к собственно сочинению Приска.

Первый компендиум издания заполнили 49 эксцерптов (в соответствии с нумерацией Кароллы - ехс. 1-49). Поскольку итальянская исследовательница использует все сохранившиеся рукописи, содержащие эксцерпты Константина VII, ею презентуется весьма аутентичный текст, сопровождаемый подробным критическим аппаратом, в основу которого положена добротно реконструированная стемма. Хотя нумерация эксцерптов содержит элементы сумбура. В частности, имеют место четыре эксцерпта (!) под номером 1, относящиеся к разным текстам [10, ехс. 1, exc. 1.1, ехс. 1a, ехс. 1b]. Эксцерпты 1 и 1.1 (идентичны c fr. 2 издания Блокли [4, fr. 2]) касаются царя гуннов Руа, то есть речь в данном случае, скорее, идет об одном (и единственном на этот счет) фрагменте (так полагает и Блокли). Но при этом под номером ехс. 1 оказываются два совершенно разных по содержанию фрагмента - об осадах Новидумума $[10$, ехс. 1a $=4$. fr. 5] и Наисса [10, ехс. $1 b=4$. fr. 6.2]. Стоит учесть, что литерами «а» и «b» скорее обозначают альтернатив- 
ные версии одного и того же текста, а не два разных текста (в данном случае предпочтительнее очередность, предлагаемая Блокли: fr. 5 и fr. 6.2).

Второй компендиум издания презентует эксцерпты Fragmenta dubia [10, p. 83-111]. Цифровые обозначения этих пассажей даны с учетом нумерации фрагментов, содержащихся в предыдущем разделе, то есть с fr. 50 по fr. 83. Смена терминологии при именовании нового раздела понятна, но оптимальным решением для реализации целей издания не является. Как и вытекает из названия раздела, в него входят тексты из самых разных трудов, с разной степенью вероятности восходящие к Приску. По большей части отдельные фрагменты этого ряда уже нашли место в изданиях Борнманна и Блокли, и абсолютно новые находки такого рода для идентификации с текстами Приска можно считать редкостью. Но некоторые фрагменты, которые Блокли считает текстами Приска, Каролла отклоняет - например, fr. 3.1. Поскольку издание Кароллы не имеет комментария (как и другие издания Тойбнеровской серии), то сохраняются вопросы о причинах принятия во внимание одних эксцерптов и отклонения других. Издание Кароллы содержит прекрасные indices nominum, locorum и fontium fragmentorum dubiorum, но в нем нет необходимого comparatio numerorum, который мог бы облегчить сравнение отдельных мест издания с изданиями Борнманна и Блокли.

Формат рецензии не позволяет обсудить все изданные Кароллой фрагменты, но уместен ряд наблюдений по поводу возможных выводов из их содержания, проистекающих, в том числе, из методики издательской презентации некоторых эксцерптов ${ }^{2}$. Новейший же

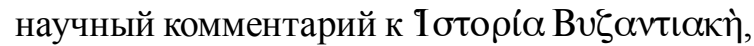
как и прежде, остается благим пожеланием.

Прежде всего интересны заслужившие внимание Борнманна (но не Блокли) те места текста, которые относятся к описанию дипломатической деятельности на Востоке магистра войск Анатолия [9, р. 84-86]. В частности, два повествующих об Анатолии пассажа, содержащиеся в «Войне с персами» Прокопия Кесарийского и в «Хронографии» Феофана, вполне могли проистекать из сочинения Панийца [9, p. 85; 10, fr. 54, 59]. Спорно толь- ко, что fr. 54 говорит о событиях 428 г., но нет

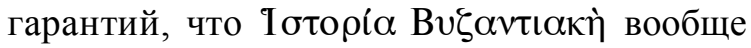
охватывала то время. В целом же обилие деталей в обоих фрагментах явно указывает на информированность и компетентность автора протографа, которого вполне можно идентифицировать с Приском.

Напротив, весьма сложен комплекс вопросов, связанных с fr. 66b. Каролла хотя и помечает курсивом то обстоятельство, что первый пассаж фрагмента вряд ли напрямую восходит к сочинению Панийца, но, как и Блокли, цитирует целиком соответствующее место из «Войн» Прокопия, не предпринимая какоголибо источниковедческого или фактологического анализа [10, p. 94-95]. Д. Бродка предположил, что здесь мы имеем дело с двумя эксцерптами из сочинения Приска. В самом деле, сообщение Прокопия, о котором идет речь [11, I, 4. 29-35], состоит из двух частей публицистического введения [11, I, 4. 29], подчеркивающего могущество Аттилы, и сообщения о взятии гуннами Аквилеи [11, I, 4. 30-35]. Бродка полагает, что целью Прокопия в данном случае было создать впечатление об опустошении Аттилой всей Европы, ибо после гибели Аэция гуннов никто не мог остановить. Дескать, и на Западе и на Востоке склонились перед царем гуннов и платили ему трибут [11, II, 4. 29]. Такого рода констатация действительно выглядит обобщением высочайшего уровня успехов Аттилы. Прокопий, как полагает польский историк, явно работал с текстом, который завершал историю царя гуннов подобного рода резюме, а затем ошибочно увязал эту публицистику со смертью Аэция. Получается, что Прокопий исходил из идейно-политической концепции, характеризующей Аэция как последнего оплота против варваров, при жизни которого римляне еще могли сих варваров побеждать. Примечательно (и это ценное наблюдение), что Прокопий даже не пытался верифицировать эту концепцию.

По этой причине хронологическая последовательность событий в данном случае роли для него не играет - выдающийся историк VI в. игнорирует тот факт, что Аттила еще при жизни Аэция разгромил несколько важных городов Северной Италии. Более того - Прокопий почти не уделяет внимания византийс- 
ко-гуннским конфликтам в трагические для империи 40-е гг. V века. Можно, конечно, полагать (как это делает Бродка), что хронологическая аберрация в сообщении Кесарийца проистекает из небрежности. Но нельзя избавиться от ощущения, что он сконструировал определенную последовательность из не связанных друг с другом подлинных событий, чтобы презентовать определенную мысль: гибель Аэция, последней надежды Запада, имела для Западной Римской империи катастрофические последствия. Подчеркивая же успехи Аттилы, Прокопий делает этот тезис еще нагляднее. Подключение историком к данному пассажу сведений об Аттиле и взятии Аквилеи гуннами свидетельствует о литературной конструкции, в которой принцип наглядности приоритетнее достоверности. В недостоверной же констатации смерти Аэция до смерти Аттилы можно видеть две причины: a) образ Аэция как последнего оплота против варваров, б) слабые представления автора об истории гуннов. В таком случае получается, что в первой части пассажа [11, II, 4. 29] Прокопий отчасти исходит из данных исторического труда Приска или из эпитомы Приска (возможно, редакции Евстафия Эпифанейского), где описывается смерть Аттилы. Напротив, во второй части пассажа [11, II, 4. 30-35] Кесариец обращается к описанию вторжения гуннов в Италию. У Приска это сообщение явно стояло до констатации как смерти Аэция, так и смерти царя гуннов.

Итак, по Прокопию, после убийства Аэция Европа стала беззащитной и Аттила не встречал серьезного сопротивления. Рисуется яркая, драматичная картина, однако лишенная достоверности из-за хронологической аберрации. Такого рода концепция имеет сходство с толкованием тех же событий в «Хрониконе» комита Марцеллина [8, а. 454.2]. Убийство Аэция рассматривается византийским хронистом как решающий момент в истории Запада, ибо оно повлекло события, завершившиеся падением Западной Римской империи. Благодаря такому взгляду историку не нужно думать о точной хронологии, а следует сосредоточиться на соответствующей эвристике и расположении материала - для конструирования связующих линий сюжета и непротиворечивой причинно-следственной картины.
Не исключено, что концепция об Аэции как оплоте против варваров в грекоязычной традиции восходит именно к Приску. Ее следы можно обнаружить не только у Прокопия, но и у Иоанна Антиохийского. Иоанн, как известно, описал обстоятельства убийства Аэция весьма подробно. С определенными оговорками можно предполагать, что этот рассказ восходит непосредственно к Приску.

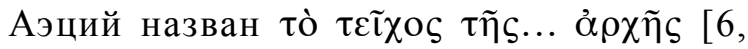
fr. 293. 1, p. 292. 18-19; 10, fr. 69, p. 97. 17-18] как во фрагменте, соотносимом с сочинением Приска, так и Иоанном Антиохийским. Ка-

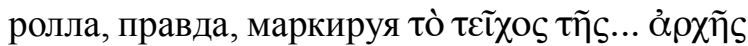
курсивом, отказывает Приску в авторстве этих слов, но без какой-либо аргументации. Обстоятельства гибели Аэция Приск преподносит довольно объективно, в прагматичных категориях. Такое описание в качестве образца использует и Иоанн. Следует, однако, учесть, что иное, скорее «романтическое», описание тех же событий, которое есть у Прокопия в Excerpta Salmasiana и в «Суде», также может проистекать из труда Панийца, где оно, возможно, играло роль альтернативного толкования произошедшего. Вероятнее, конечно, что такого рода редакция возникла уже в традиции после Приска.

Результаты. В целом новое издание, выполненное итальянским филологом, является серьезным вкладом в исследование не только творчества Приска Панийского, но и всей позднеантичной греческой историографической традиции. Специалисты получили добротный и надежный текст, из которого трудно изъять отдельные эксцерпты - в силу его сильной внутренней логики. Издатель предложил также в качестве гипотетически соотносимых с именем Приска несколько новых эксцерптов. Однако Каролла лишь в ограниченной мере выходит за пределы результатов более ранних исследований. Очередность эксцерптов и фрагментов не в каждом случае убедительна. То же самое относится к фрагментам, справедливо именуемым dubia. Поэтому издание, выполненное Кароллой, вряд ли способно полностью заменить отличное editio Р. Блокли. По этой же причине оно играет роль дополнительного импульса к дальнейшим изысканиям в сфере ранневизантийской светской литературы. 


\section{ПРИМЕЧАНИЯ}

1 Первое издание вышло в 2008 году.

2 О связи анализа содержания отдельных мест сочинения Панийца с установлением очередности его фрагментов см. конкретные примеры: [2; 12].

\section{СПИСОК ЛИТЕРАТУРЫ}

1. Baldwin, B. Priscus of Panium / B. Baldwin // Byzantion. - 1980. - No. 50. - P. 18-61.

2. Benedicty, R. Die historische Authentizitát eines Berichtes des Priskos / R. Benedicty // Jahrbuch der Österreichischen byzantinischen Gesellschaft. 1964. - Bd. XIII. - S. 1-8.

3. Blockley, R. C. The Fragmentary Classicising Historians of the Later Roman Empire. Eunapius, Olympiodorus, Priscus and Malchus. Vol. II. Text, Translation and Historiographical Notes / R. C. Blockley. - Liverpool : Francis Cairns, 1983. $-515 \mathrm{p}$.

4. Blockley, R. C. The Development of Greek Historiography : Priscus, Malchus, Candidus / R. C. Blockley // Greek and Roman Historiography in Late Antiquity. Fourth to Sixth Century A.D. / ed. G. Marasco. - Leiden, Boston : Brill, 2003. - P. 289-315.

5. Brodka, D. Attila und Aetius. Zur PriskosTradition bei Prokopios von Kaisareia / D. Brodka // From Antiquity to Modern Times. Classical Poetry and It Modern Reception. Essays in Honour of S. Stabryła / ed. by J. Styka. - Kraków : Księgarnia Akademicka, 2007. - S. 149-158.

6. Ioannis Antiocheni Fragmenta ex Historia chronica / ed. by U. Roberto. - Berlin, New York : Walter de Gruyter, 2005. - CCXI, 661 p.

7. Maas, M. Fugitives and ethnography in Priscus of Panium / M. Maas // Byzantine and Modern Greeck Studies. - 1995. - Vol. 19, no. 1. - P. 146-160.

8. Marcellini comitis Chronicon // Chronica Minora. Saec. IV, V, VI, VII. Vol. II / ed. Th. Mommsen. Berolini : Apud Weidmannos, 1894. - P. 37-108. (Monumenta Germaniae Historica. Auctores antiquissimi ; T. XI).

9. Martindale, J. R. The Prosopography of the Later Roman Empire. Vol. II A.D. 395-527 / J. R. Martindale. - New York : Cambridge University Press, 1980. - $1342 \mathrm{p}$.

10. Priscus Panita. Excerpta et fragmenta / ed. by P. Carolla. - Berolini et Novi Eboraci : Walter de Gruyter, 2017. - XLVIII, 140 p.

11. Procopii Caesariensis De bello Vandalico // Procopii Caesariensis Opera omnia. Vol. I / ed. J. Haury. - Lipsiae : Teubner Verlag, 1962. - P. 350-416.

12. Traina, G. De Synésios à Priscus: aperçus sur la connaissance de la 'barbarie' hunnique (fin du IVe- milieu du Ve siècle), 285-290 / G. Traina // L’Armée romaine et les barbares du IIIe au VIIe siècle / ed. F. Vallet \& M. Kazansky. - Rouen : Association Française d'Archéologie Mérovingienne and Musée des Antiquités Nationales, 1993. - P. 285-290.

\section{REFERENCES}

1. Baldwin B. Priscus of Panium. Byzantion, 1980, vol. 50, pp. 18-61.

2. Benedicty R. Die historische Authentizitát eines Berichtes des Priskos. Jahrbuch der Österreichischen byzantinischen Gesellschaft, 1964, vol. XIII, pp. 1-8.

3. Blockley R.C. The Fragmentary Classicising Historians of the Later Roman Empire. Eunapius, Olympiodorus, Priscus and Malchus. Vol. II. Text, Translation and Historiographical Notes. Liverpool, Francis Cairns, 1983. 515 p.

4. Blockley R.C. The Development of Greek Historiography: Priscus, Malchus, Candidus. Marasco G., ed. Greek and Roman Historiography in Late Antiquity. Fourth to Sixth Century A.D. Leiden, Boston, Brill, 2003, pp. 289-315.

5. Brodka D. Attila und Aetius. Zur PriskosTradition bei Prokopios von Kaisareia. Styka J., ed. From Antiquity to Modern Times. Classical Poetry and It Modern Reception. Essays in Honour of S. Stabryta. Kraków, Księgarnia Akademicka, 2007, pp. 149-158.

6. Roberto U., ed. Ioannis Antiocheni Fragmenta ex Historia chronica. Berlin, New York, Walter de Gruyter, 2005. CCXI, 661 p.

7. Maas M. Fugitives and ethnography in Priscus of Panium. Byzantine and Modern Greeck Studies, 1995, vol. 19, no. 1, pp. 146-160.

8. Marcellini comitis Chronicon. Mommsen Th., ed. Chronica Minora. Saec. IV, V, VI, VII. Vol. II. Berolini, Apud Weidmannos, 1894. pp. 37-108. (Monumenta Germaniae Historica. Auctores antiquissimi. T. XI).

9. Martindale J.R. The Prosopography of the Later Roman Empire. Vol. II A.D. 395-527. New York, Cambridge University Press, 1980. 1342 p.

10. Carolla P., ed. Priscus Panita. Excerpta et fragmenta. Berolini et Novi Eboraci, Walter de Gruyter, 2017. XLVIII, $140 \mathrm{p}$.

11. Đrocopii Caesariensis De bello Vandalico. Haury J., ed. Procopii Caesariensis Opera omnia. Vol. I. Lipsiae, Teubner Verlag, 1962, pp. 350-416.

12. Traina G. De Synésios à Priscus: aperçus sur la connaissance de la 'barbarie' hunnique (fin du IVemilieu du Ve siècle), 285-290. Vallet F., Kazansky M., eds. L'Armée romaine et les barbares du IIIe au VIIe siècle. Rouen, Association Française d'Archéologie Mérovingienne and Musée des Antiquités Nationales, 1993, pp. 285-290. 


\section{Information About the Author}

Alexander S. Kozlov, Candidate of Sciences (History), Associate Professor, Department of History of the Ancient World and the Middle Ages, Ural Federal University named after the first President of Russia B.N. Yeltsin, Prosp. Lenina, 51, 620014 Yekaterinburg, Russian Federation, alarich@olympus.ru, https://orcid.org/0000-0002-9203-9169

\section{Информация об авторе}

Александр Сергеевич Козлов, кандидат исторических наук, доцент кафедры истории Древнего мира и Средних веков, Уральский федеральный университет им. первого Президента России Б.Н. Ельцина, просп. Ленина, 51, 620014 г. Екатеринбург, Российская Федерация, alarich@olympus.ru, https://orcid.org/0000-0002-9203-9169 